\title{
Common best proximity points results for new proximal $C$-contraction mappings
}

\author{
Parvaneh Lo'lo'1, Seiyed Mansour Vaezpour ${ }^{2}$ and Reza Saadati ${ }^{*}$
}

\author{
"Correspondence: rsaadati@eml.cc \\ ${ }^{3}$ Department of Mathematics, Iran \\ University of Science and \\ Technology, Tehran, Iran \\ Full list of author information is \\ available at the end of the article
}

\begin{abstract}
We define a new version of proximal C-contraction and prove the existence and uniqueness of a common best proximity point for a pair of non-self functions. Then we apply our main results to get some fixed point theorems and we give an example to illustrate our results.
\end{abstract}

MSC: Primary 90C26; 90C30; secondary 47H09; 47H10

Keywords: common best proximity point; triangular $\alpha$-proximal admissible; proximal C-contraction

\section{Introduction and preliminaries}

Consider a pair $(A, B)$ of nonempty subsets of a metric space $(X, d)$. Assume that $f$ is a function from $A$ into $B$. An $w \in A$ is said to be a best proximity point whenever $d(w, f w)=$ $d(A, B)$, where $d(A, B)=\inf \{d(s, t): s \in A, t \in B\}$.

Best proximity point theory of non-self functions was initiated by Fan [1] and Kirk et al. [2]; see also [3-13]. In this paper, we generalize some results of Kumam et al. [14] to obtain some new common best proximity point theorems. Next, by an example and some fixed point results, we support our main results and show some applications of them.

Definition 1.1 Consider non-self functions $f_{1}, f_{2}, \ldots, f_{n}: A \rightarrow B$. We say the a point $s \in A$ is a common best proximity point of $f_{1}, f_{2}, \ldots, f_{n}$ if

$$
d\left(s, f_{1} s\right)=d\left(s, f_{2} s\right)=\cdots=d\left(s, f_{n} s\right)=d(A, B) .
$$

Definition $1.2([14])$ Let $(X, d)$ be a metric space and $\emptyset \neq A, B \subset X$. We say the pair $(A, B)$ has the $V$-property if for every sequence $\left\{t_{n}\right\}$ of $B$ satisfying $d\left(s, t_{n}\right) \rightarrow d(s, B)$ for some $s \in A$, there exists a $t \in B$ such that $d(s, t)=d(s, B)$.

\section{Main results}

We denote by $\Psi$ the family of all continuous functions from $[0,+\infty) \times[0,+\infty)$ to $[0,+\infty)$ such that $\psi(u, v)=0$ if and only if $u=v=0$ where $\psi \in \Psi$.

Definition 2.1 Let $(X, d)$ be a metric space, $\emptyset \neq A, B \subset X, \alpha: A \times A \rightarrow[0, \infty)$ a function and $f, g: A \rightarrow B$ non-self mappings. We say that $(f, g)$ is a triangular $\alpha$-proximal admissible

(c) 2016 Lo'lo' et al. This article is distributed under the terms of the Creative Commons Attribution 4.0 International License (http://creativecommons.org/licenses/by/4.0/), which permits unrestricted use, distribution, and reproduction in any medium, provided you give appropriate credit to the original author(s) and the source, provide a link to the Creative Commons license, and indicate if changes were made. 
pair, if for all $p, q, r, t_{1}, t_{2}, s_{1}, s_{2} \in A$,

$$
\begin{aligned}
& T_{1}:\left\{\begin{array}{l}
\alpha\left(t_{1}, t_{2}\right) \geq 1, \\
d\left(s_{1}, f t_{1}\right)=d(A, B), \quad \Rightarrow \quad \alpha\left(s_{1}, s_{2}\right) \geq 1, \\
d\left(s_{2}, g t_{2}\right)=d(A, B)
\end{array}\right. \\
& T_{2}:\left\{\begin{array}{l}
\alpha(p, r) \geq 1, \\
\alpha(r, q) \geq 1
\end{array} \quad \Longrightarrow \quad \alpha(p, q) \geq 1 .\right.
\end{aligned}
$$

Let $(X, d)$ be a metric space and $\emptyset \neq A, B \subset X$. We define

$$
\begin{aligned}
& A_{0}=\{s \in A: d(s, t)=d(A, B) \text { for some } t \in B\}, \\
& B_{0}=\{t \in B: d(s, t)=d(A, B) \text { for some } s \in A\} .
\end{aligned}
$$

Definition 2.2 Let $(X, d)$ be a metric space, $\emptyset \neq A, B \subset X$, and $f, g: A \rightarrow B$ non-self mappings. We say that $(f, g)$ is a generalized proximal $C$-contraction pair if, for all $s, t, p, q \in A$,

$$
\left.\begin{array}{l}
d(s, f p)=d(A, B), \\
d(t, g q)=d(A, B)
\end{array}\right\} \quad \Longrightarrow \quad d(s, t) \leq \frac{1}{2}(d(p, t)+d(q, s))-\psi(d(p, t), d(q, s))
$$

in which $\psi \in \Psi$.

Definition 2.3 Let $(X, d)$ be a metric space, $\emptyset \neq A, B \subset X, \alpha: A \times A \rightarrow[0, \infty)$ a function and $f, g: A \rightarrow B$ non-self functions. If, for all $s, t, p, q \in A$,

$$
\left\{\begin{array}{l}
d(s, f p)=d(A, B) \\
d(t, g q)=d(A, B)
\end{array}\right.
$$

imply

$$
\alpha(p, q) d(s, t) \leq \frac{1}{2}(d(p, t)+d(q, s))-\psi(d(p, t), d(q, s))
$$

then $(f, g)$ is said to be an $\alpha$-proximal $C 1$-contraction pair.

If in the definition above, we replace (2) by

$$
(\alpha(p, q)+l)^{d(s, t)} \leq(l+1)^{\frac{1}{2}(d(p, t)+d(q, s))-\psi(d(p, t), d(q, s))},
$$

where $l>0$, then $(f, g)$ is said to be an $\alpha$-proximal $C 2$-contraction pair.

Theorem 2.4 Let $(X, d)$ be a metric space and $\emptyset \neq A, B \subset X$. Let $A$ be complete and $A_{0}$ nonempty set. Moreover, assume that the non-self functions $f, g: A \rightarrow B$ satisfy:

(i) $f$, gare continuous,

(ii) $f\left(A_{0}\right) \subset B_{0}$ and $g\left(A_{0}\right) \subset B_{0}$,

(iii) $(f, g)$ is a generalized proximal $C$-contraction pair,

(iv) there exist $s_{0}, s_{1} \in A_{0}$ such that $d\left(s_{1}, s_{0}\right)=d(A, B)$.

Then the functions $f$ and $g$ have a unique common best proximity point. 
Proof From (iv) we can get $s_{0}, s_{1} \in A_{0}$ such that

$$
d\left(s_{1}, f s_{0}\right)=d(A, B)
$$

Since $g\left(A_{0}\right) \subset B_{0}$, there exists $s_{2} \in A_{0}$ such that $d\left(s_{2}, g s_{1}\right)=d(A, B)$.

We continue this process and construct a sequence $\left\{s_{n}\right\}$ such that

$$
\left\{\begin{array}{l}
d\left(s_{2 n+1}, f s_{2 n}\right)=d(A, B), \\
d\left(s_{2 n+2}, g s_{2 n+1}\right)=d(A, B)
\end{array}\right.
$$

for each $n \in \mathbb{N}$.

We divide our further derivation into four steps.

Step 1. We have

$$
\lim _{n \rightarrow \infty} d\left(s_{n}, s_{n+1}\right)=0
$$

Put $s=s_{2 n+1}$ and $t=s_{2 n+2}$. From (1), we get

$$
\begin{aligned}
d\left(s_{2 n+1}, s_{2 n+2}\right) & =\frac{1}{2}\left(d\left(s_{2 n}, s_{2 n+2}\right)+d\left(s_{2 n+1}, s_{2 n+1}\right)\right)-\psi\left(d\left(s_{2 n}, s_{2 n+2}\right), d\left(s_{2 n+1}, s_{2 n+1}\right)\right) \\
& =\frac{1}{2} d\left(s_{2 n}, s_{2 n+2}\right)-\psi\left(d\left(s_{2 n}, s_{2 n+2}\right), 0\right) \\
& \leq \frac{1}{2} d\left(s_{2 n}, s_{2 n+2}\right) \\
& \leq \frac{1}{2}\left(d\left(s_{2 n}, s_{2 n+1}\right)+d\left(s_{2 n+1}, s_{2 n+2}\right)\right)
\end{aligned}
$$

which implies $d\left(s_{2 n+1}, s_{2 n+2}\right) \leq d\left(s_{2 n}, s_{2 n+1}\right)$.

Now, if we put $d_{n}:=d\left(s_{n}, s_{n+1}\right)$, then we get $d_{2 n+1} \leq d_{2 n}$. Also, we have $d_{2 n+2} \leq d_{2 n+1}$, which implies that the sequence $\left\{d_{n}\right\}$ is decreasing and so there is a $d \geq 0$ such that $d_{n} \rightarrow d$ as $n \rightarrow \infty$. Now, take $n \rightarrow \infty$ in (6) and get

$$
d \leq \frac{1}{2} \lim _{n \rightarrow \infty} d\left(s_{2 n}, s_{2 n+2}\right) \leq \frac{1}{2}(d+d)=d,
$$

that is,

$$
\lim _{n \rightarrow \infty} d\left(s_{2 n}, s_{2 n+2}\right)=2 d
$$

Take again $n \rightarrow \infty$ in (6). By (7) and the continuity of $\psi$, we get

$$
d \leq d-\psi(2 d, 0)
$$

and so $\psi(2 d, 0)=0$. By the properties of $\psi$, we get $d=0$.

Step 2. We claim that $\left\{s_{n}\right\}$ is a Cauchy sequence. By (5), we show that the subsequence $\left\{s_{2 n}\right\}$ of $\left\{s_{n}\right\}$ is a Cauchy sequence in $A_{0}$. Contrarily, let there exists an $\epsilon>0$ for which the subsequences $\left\{s_{2 m(k)}\right\}$ and $\left\{s_{2 n(k)}\right\}$ of $\left\{s_{2 n}\right\}$ such that $n(k)$ is the smallest integer satisfying, for all $k>0$,

$$
n(k)>m(k)>k \quad \text { implies } \quad d\left(s_{2 m(k)}, s_{2 n(k)}\right) \geq \epsilon,
$$


which would imply that

$$
d\left(s_{2 m(k)}, s_{2 n(k)-2}\right)<\epsilon .
$$

Using the triangular inequality, (8), and (9), we would get

$$
\begin{aligned}
\epsilon & \leq d\left(s_{2 m(k)}, s_{2 n(k)}\right) \leq d\left(s_{2 m(k)}, s_{2 n(k)-2}\right)+d\left(s_{2 n(k)-2}, s_{2 n(k)-1}\right)+d\left(s_{2 n(k)-1}, s_{2 n(k)}\right) \\
& <\epsilon+d\left(s_{2 n(k)-2}, s_{2 n(k)-1}\right)+d\left(s_{2 n(k)-1}, s_{2 n(k)}\right) .
\end{aligned}
$$

Letting $k \rightarrow \infty$ in the above inequality and using (5), we would get

$$
\lim _{k \rightarrow \infty} d\left(s_{2 m(k)}, s_{2 n(k)}\right)=\epsilon
$$

On the other hand, we have

$$
d\left(s_{2 m(k)}, s_{2 n(k)}\right) \leq d\left(s_{2 m(k)}, s_{2 n(k)+1}\right)+d\left(s_{2 n(k)+1}, s_{2 n(k)}\right) .
$$

Now, we would have

$$
\epsilon \leq \lim _{n \rightarrow \infty} d\left(s_{2 m(k)}, s_{2 n(k)+1}\right)
$$

By the triangular inequality, we have

$$
d\left(s_{2 m(k)}, s_{2 n(k)}\right) \leq d\left(s_{2 m(k)}, s_{2 m(k)-1}\right)+d\left(s_{2 m(k)-1}, s_{2 n(k)+1}\right)+d\left(s_{2 n(k)+1}, s_{2 n(k)}\right) .
$$

Letting again $k \rightarrow \infty$ in the above inequality and using (5) and (10), we would get

$$
\epsilon \leq \lim _{k \rightarrow \infty} d\left(s_{2 m(k)-1}, s_{2 n(k)+1}\right)
$$

Also, we can get $\lim _{k \rightarrow \infty} d\left(s_{2 m(k)-1}, s_{2 n(k)+1}\right) \leq \epsilon$, and so

$$
\lim _{n \rightarrow \infty} d\left(s_{2 m(k)-1}, s_{2 n(k)+1}\right)=\epsilon .
$$

From (1) we have

$$
\begin{aligned}
d\left(s_{2 n(k)+1}, s_{2 m(k)}\right) \leq & \frac{1}{2}\left(d\left(s_{2 n(k)}, s_{2 m(k)}\right)+d\left(s_{2 n(k)+1}, s_{2 m(k)-1}\right)\right) \\
& -\psi\left(d\left(s_{2 n(k)}, s_{2 m(k)}\right), d\left(s_{2 n(k)+1}, s_{2 m(k)-1}\right)\right) .
\end{aligned}
$$

Taking $k \rightarrow \infty$ in the above inequality and using (10), (11), (12), and the continuity of $\psi$, we would obtain

$$
\epsilon \leq \frac{1}{2}(\epsilon+\epsilon)-\psi(\epsilon, \epsilon)
$$

and therefore $\psi(\epsilon, \epsilon)=0$, which would imply $\epsilon=0$, a contradiction. Thus, $\left\{s_{n}\right\}$ is a Cauchy sequence. Since $A$ is complete, there is a $z \in A$ such that $s_{n} \rightarrow z$. 
Step 3. Now, from

$$
d\left(s_{2 n+1}, f s_{2 n}\right)=d(A, B), \quad d\left(s_{2 n+2}, g s_{2 n+1}\right)=d(A, B),
$$

taking $n \rightarrow \infty$ and by continuity of $f$ and $g$, we have $d(z, f z)=d(z, g z)=d(A, B)$. So, $z$ is a common best proximity point of the mappings $f$ and $g$.

Step 4 . Now, let $f$ and $g$ have another common best proximity point, say $w$, such that

$$
d(w, f w)=d(w, g w)=d(A, B) .
$$

From (1) we have

$$
\begin{aligned}
d(z, w) & \leq \frac{1}{2}(d(z, w)+d(w, z))-\psi(d(z, w), d(w, z)) \\
& =d(z, w)-\psi(d(z, w), d(z, w))
\end{aligned}
$$

whence $d(z, w)=0$, and therefore $z=w$.

Theorem 2.5 Let $(X, d)$ be a metric space and $\emptyset \neq A, B \subset X$ such that $A$ is complete and $A_{0}$ is nonempty. Moreover, suppose that the non-self functions $f, g: A \rightarrow B$ satisfy:

(i) $f$, $g$ are continuous,

(ii) $f\left(A_{0}\right) \subset B_{0}$ and $g\left(A_{0}\right) \subset B_{0}$,

(iii) $(f, g)$ is an $\alpha$-proximal C1-contraction pair or an $\alpha$-proximal C2-contraction pair,

(iv) $(f, g)$ is a triangular $\alpha$-proximal admissible pair,

(iv) there exist $s_{0}, s_{1} \in A_{0}$ such that $d\left(s_{1}, f s_{0}\right)=d(A, B), \alpha\left(s_{1}, s_{0}\right) \geq 1$.

Then $f$ and $g$ have a common best proximity point. Furthermore, if $z, w \in X$ are common best proximity points and $\alpha(z, w) \geq 1$, then common best proximity point is unique.

Proof By (iv), we can find $s_{0}, s_{1} \in A_{0}$ such that

$$
d\left(s_{1}, f s_{0}\right)=d(A, B), \quad \alpha\left(s_{1}, s_{0}\right) \geq 1 .
$$

Define the sequence $\left\{s_{n}\right\}$ as in (4) of Theorem 2.4. Since $(f, g)$ is triangular $\alpha$-proximal admissible, we have $\alpha\left(s_{n}, s_{n+1}\right) \geq 1$. Then

$$
\left\{\begin{array}{l}
\alpha\left(s_{n}, s_{n+1}\right) \geq 1, \\
d\left(s_{2 n+1}, f s_{2 n}\right)=d(A, B), \\
d\left(s_{2 n+2}, g s_{2 n+1}\right)=d(A, B) .
\end{array}\right.
$$

If $s=s_{2 n+1}, t=s_{2 n+2}, p=s_{2 n}, q=s_{2 n+1}$, and $(f, g)$ is an $\alpha$-proximal $C 1$-contraction pair or an $\alpha$-proximal $C 2$-contraction pair, then $(f, g)$ is a generalized proximal $C$-contraction pair. Then Step 1 of the proof of Theorem 2.4 implies that $\lim _{n \rightarrow \infty} d\left(s_{n}, s_{n+1}\right)=0$.

Now we prove that

$$
\alpha\left(s_{2 m(k)-1}, s_{2 n(k)}\right) \geq 1, \quad n(k)>m(k)>k .
$$

Since $(f, g)$ is triangular $\alpha$-proximal admissible and

$$
\left\{\begin{array}{l}
\alpha\left(s_{2 m(k)-1}, s_{2 m(k)}\right) \geq 1, \\
\alpha\left(s_{2 m(k)}, s_{2 m(k)+1}\right) \geq 1,
\end{array}\right.
$$


from $\left(T_{2}\right)$ of Definition 2.1, we have

$$
\alpha\left(s_{2 m(k)-1}, s_{2 m(k)+1}\right) \geq 1 .
$$

Again, since $(f, g)$ is triangular $\alpha$-proximal admissible and

$$
\left\{\begin{array}{l}
\alpha\left(s_{2 m(k)-1}, s_{2 m(k)+1}\right) \geq 1 \\
\alpha\left(s_{2 m(k)+1}, s_{2 m(k)+2}\right) \geq 1
\end{array}\right.
$$

from $\left(T_{2}\right)$ of Definition 2.1 again, we have

$$
\alpha\left(s_{2 m(k)-1}, s_{2 m(k)+2}\right) \geq 1 .
$$

By continuing this process, we get (16). If $s=s_{2 n(k)+1}, t=s_{2 m(k)}, p=s_{2 n(k)}, q=s_{2 m(k)-1}$, then $\alpha$-proximal $C 1$-contraction ( $C 2$-contraction) pair $(f, g)$ is a generalized proximal $C$-contraction pair. Therefore by Step 2 of Theorem 2.4, there exists a $z \in A$ such that $s_{n} \rightarrow z$. Step 3 of Theorem 2.4 and continuity of $f$ and $g$ immediately imply that $f$ and $g$ have a common best proximity point $z$. If $w$ is another common best proximity point of $(f, g)$, then, since $\alpha(z, w) \geq 1$, Step 4 implies that $z=w$.

Definition 2.6 Let $\alpha: X \times X \rightarrow(-\infty,+\infty)$ be a function and $f, g: X \rightarrow X$ self mappings. We say that $(f, g)$ is a triangular $\alpha$-admissible pair if

(i) $p, q \in X, \alpha(p, q) \geq 1 \Longrightarrow \alpha(f p, g q) \geq 1$ or $\alpha(g p, f q) \geq 1$,

(ii) $p, q, r \in X,\left\{\begin{array}{l}\alpha(p, r) \geq 1, \\ \alpha(r, q) \geq 1,\end{array} \Longrightarrow \alpha(p, q) \geq 1\right.$.

The following corollary is a consequence of the last theorem.

Corollary 2.7 Let $(X, d)$ be a complete metric space and $f, g: X \rightarrow X$. Moreover, let the self functions $f$ and $g$ satisfy:

(i) $f$ and $g$ are continuous,

(ii) there exists $s_{0} \in X$ such that $\alpha\left(s_{0}, f s_{0}\right) \geq 1$,

(iii) $(f, g)$ is a triangular $\alpha$-admissible pair,

(iv) for all $p, q \in X, \alpha(p, q) d(f p, g q) \leq \frac{1}{2}(d(p, g q)+d(q, f p))-\psi(d(p, g q), d(q, f p))$ $\left(\right.$ or $\left.(\alpha(p, q)+l)^{d(f p, g q)} \leq(l+1)^{\frac{1}{2}(d(p, g q)+d(q, f p))-\psi(d(p, g q), d(q, f p))}\right)$.

Then $f$ and $g$ have a common fixed point. Moreover, if $x, y \in X$ are common fixed points and $\alpha(x, y) \geq 1$, then the common fixed point off and $g$ is unique, that is, $x=y$.

Now, we remove the continuity hypothesis of $f$ and $g$, and get the following theorem.

Theorem 2.8 Let $(X, d)$ be a metric space and $\emptyset \neq A, B \subset X$. Let $A$ be complete, the pair $(A, B)$ have the $V$-property, and $A_{0}$ be nonempty. Moreover, suppose that the non-self mappings $f, g: A \rightarrow B$ satisfy:

(i) $f\left(A_{0}\right) \subset B_{0}$ and $g\left(A_{0}\right) \subset B_{0}$,

(ii) $(f, g)$ is a generalized proximal $C$-contraction pair,

(iii) there are $s_{0}, s_{1} \in A_{0}$ such that $d\left(s_{1}, f s_{0}\right)=d(A, B)$.

Then the functions $f$ and $g$ have unique common best proximity point. 
Proof By Theorem 2.4, there is a Cauchy sequence $\left\{s_{n}\right\} \subset A$ and $z \in A$ such that (4) holds and $s_{n} \rightarrow z$. Moreover, we have

$$
\begin{aligned}
d(z, B) & \leq d\left(z, f_{s_{2 n}}\right) \\
& \leq d\left(z, s_{2 n+1}\right)+d\left(s_{2 n+1}, f s_{2 n}\right) \\
& =d\left(z, s_{2 n+1}\right)+d(A, B) .
\end{aligned}
$$

We take $n \rightarrow \infty$ in the above inequality, and we get

$$
\lim _{n \rightarrow \infty} d\left(z, f_{s_{n}}\right)=d(z, B)=d(A, B) .
$$

Since the pair $(A, B)$ has the $V$-property, there is a $p \in B$ such that $d(z, p)=d(A, B)$ and so $z \in A_{0}$. Moreover, since $f\left(A_{0}\right) \subset B_{0}$, there is a $q \in A$ such that

$$
d(q, f z)=d(A, B) .
$$

Furthermore $d\left(s_{2 n+2}, g s_{2 n+1}\right)=d(A, B)$ for every $n \in \mathbb{N}$.

Since $(f, g)$ is a generalized proximal $C$-contraction pair, we have

$$
d\left(q, s_{2 n+2}\right) \leq \frac{1}{2}\left(d\left(z, s_{2 n+2}\right)+d\left(s_{2 n+1}, q\right)\right)-\psi\left(d\left(z, s_{2 n+2}\right), d\left(s_{2 n+1}, q\right)\right) .
$$

Letting $n \rightarrow \infty$ in the above inequality, we have

$$
d(q, z) \leq \frac{1}{2} d(z, q)-\psi(d(z, q), 0) .
$$

Thus $d(z, q)=0$, which implies that $z=q$. Then, by (18), $z$ is a best proximity point of $f$.

Similarly, it is easy to prove that $z$ is a best proximity point of $g$. Then $z$ is a common best proximity point of the functions $f$ and $g$. By the proof of Theorem 2.4 we conclude that $f$ and $g$ have unique common best proximity point.

Theorem 2.9 Let $(X, d)$ be a metric space and $\emptyset \neq A, B \subset X$. Let $A$ be complete, the pair $(A, B)$ have the $V$-property and $A_{0}$ be a nonempty set. Moreover, suppose that the non-self functions $f, g: A \rightarrow B$ satisfy:

(i) $f\left(A_{0}\right) \subset B_{0}$ and $g\left(A_{0}\right) \subset B_{0}$,

(ii) $(f, g)$ is an $\alpha$-proximal C1-contraction pair or an $\alpha$-proximal C2-contraction pair,

(iii) $(f, g)$ is a triangular $\alpha$-proximal admissible pair,

(iv) there exist $s_{0}, s_{1} \in A_{0}$ such that $d\left(s_{1}, f s_{0}\right)=d(A, B), \alpha\left(s_{1}, s_{0}\right) \geq 1$,

(v) if $\left\{s_{n}\right\}$ is a sequence in $A$ such that $\alpha\left(s_{n}, s_{n+1}\right) \geq 1$ and $s_{n} \rightarrow s_{0}$ as $n \rightarrow \infty$, then $\alpha\left(s_{n}, s_{0}\right) \geq 1$ for all $n \in \mathbb{N} \cup\{0\}$.

Then $f$ and $g$ have a common best proximity point. Moreover, if $z, w \in X$ are common best proximity points and $\alpha(z, w) \geq 1$, then the common best proximity point is unique.

Proof We can derive from the proof of Theorem 2.5 that there exist a sequence $\left\{s_{n}\right\}$ and $z$ in $A$ such that $s_{n} \rightarrow z$ and $\alpha\left(s_{n}, s_{n+1}\right) \geq 1$. Also, by $(\mathrm{v}), \alpha\left(s_{n}, z\right) \geq 1$ for every $n \in \mathbb{N} \cup\{0\}$. Let $s=q, t=s_{2 n+2}, p=z, q=s_{2 n+1}$. If $(f, g)$ is an $\alpha$-proximal $C 1$-contraction pair or $\alpha$-proximal 
$C 2$-contraction pair, then $(f, g)$ is a generalized proximal $C$-contraction pair. Then by the proof of the last theorem, $z$ is a common best proximity of $f$ and $g$.

The following corollary is an immediate consequence of the main theorem of this section.

Corollary 2.10 Let $(X, d)$ be a complete metric space and $f, g: X \rightarrow X$. Moreover, let the selffunctions $f$ and $g$ satisfy:

(i) $(f, g)$ is a triangular $\alpha$-admissible pair,

(ii) there exists an $s_{0} \in X$ such that $\alpha\left(s_{0}, f s_{0}\right) \geq 1$,

(iii) if $\left\{s_{n}\right\}$ is a sequence in $A$ such that $\alpha\left(s_{n}, s_{n+1}\right) \geq 1$ and $s_{n} \rightarrow s_{0} \in A$ as $n \rightarrow \infty$, then $\alpha\left(s_{n}, s_{0}\right) \geq 1$ for all $n \in \mathbb{N} \cup\{0\}$,

(iv) for all $x, y \in X, \alpha(p, q) d(f p, g q) \leq \frac{1}{2}(d(p, g q)+d(q, f p))-\psi(d(p, g q), d(q, f p))$ $\left(\right.$ or $\left.(\alpha(p, q)+l)^{d(f p, g q)} \leq(l+1)^{\frac{1}{2}(d(p, g q)+d(q, f p))-\psi(d(p, g q), d(q, f p))}\right)$.

Then $f$ and $g$ have a common fixed point. Moreover, if $x, y \in X$ are common fixed points and $\alpha(x, y) \geq 1$, then the common fixed point off and $g$ is unique, that is, $x=y$.

In order to illustrate our results, we present the following example.

Example 2.11 Consider $X=\mathbb{R}$ with the usual metric $d(x, y)=|x-y|, A=\{-4,0,4\}$, and $B=\{-2,-1,2\}$. Then $A$ and $B$ are nonempty closed subsets of $X$ with $d(A, B)=1, A_{0}=\{0\}$, and $B_{0}=\{-1\}$. We define $f, g: A \rightarrow B$ by

$$
f(0)=-1, \quad f(10)=2, \quad f(-10)=-2 \quad \text { and } \quad g(x)=-1 \quad \forall x \in A,
$$

and $\psi:[0, \infty) \times[0, \infty) \rightarrow[0, \infty)$ by $\psi(s, t)=s t$.

It is immediate to see that $f\left(A_{0}\right) \subset B_{0}$ and $g\left(A_{0}\right) \subset B_{0}$. Also, if

$$
\left\{\begin{array}{l}
d(u, f p)=d(A, B)=1, \\
d(v, g q)=d(A, B)=1,
\end{array}\right.
$$

then $u=v=p=0$ and $q \in A$ and therefore (1) is satisfied. Hence all the conditions of Theorem 2.4 hold for this example and clearly 0 is the unique common best proximity of $f$ and $g$.

Example 2.12 Let $X=[0,1] \times[0,1]$ and $d$ be the Euclidean metric. Let

$$
A:=\{(0, m): 0 \leq m \leq 1\}, \quad B:=\{(1, n): 0 \leq n \leq 1\}
$$

Then $d(A, B)=1, A_{0}=A$, and $B_{0}=B$. We define $f, g: A \rightarrow B$ by

$$
f(0, m)=(1, m), \quad g(0, m)=(1,1) .
$$

Define $\alpha: A \times A \rightarrow[0, \infty)$ by

$$
\alpha(p, q)= \begin{cases}2, & \text { if } p, q \in(0,1) \times\{(0,0),(0,1)\} \\ 0, & \text { otherwise }\end{cases}
$$


and $\psi:[0, \infty) \times[0, \infty) \rightarrow[0, \infty)$ by

$$
\psi(s, t)=\frac{1}{2}(s+t) \quad \text { for all } s, t \in X
$$

Then $f\left(A_{0}\right) \subset B_{0}, g\left(A_{0}\right) \subset B_{0}$. Assume that

$$
\left\{\begin{array}{l}
d(u, f p)=d(A, B)=1, \\
d(v, g q)=d(A, B)=1 .
\end{array}\right.
$$

Hence, $u=p$ and $v=(0,1)$. If $p=(0,1)$, then $u=v$ and (2) holds. If $p \neq(0,1)$, then $\alpha(p, q)=0$ and (2) holds, which implies that $(f, g)$ is an $\alpha$-proximal $C 1$-contraction. Hence, all the hypotheses of Theorem 2.5 are satisfied. Moreover, if $\left\{s_{n}\right\}$ is a sequence such that $\alpha\left(s_{n}, s_{n+1}\right) \geq 1$ for every $n \in \mathbb{N} \cup\{0\}$ and $s_{n} \rightarrow s_{0}$, then $s_{n}=(0,1)$ for all $n \in \mathbb{N} \cup\{0\}$ and hence $s_{0}=(0,1)$. Then $\alpha\left(s_{n}, s_{0}\right) \geq 1$ for every $n \in \mathbb{N} \cup\{0\}$. Clearly, $(A, B)$ has the $V$-property and then all the conclusions of Theorem 2.9 hold. Clearly $(0,1)$ is the unique common best proximity of $f$ and $g$.

The following example shows that the triangular $\alpha$-proximal admissible condition for $(f, g)$ cannot be relaxed from Theorem 2.9.

Example 2.13 Let $X=[0,1] \times[0,1]$ and $d$ be the Euclidean metric. Let

$$
A:=\{(0, m): 0 \leq m \leq 1\}, \quad B:=\{(1, n): 0 \leq n \leq 1\} .
$$

Then $d(A, B)=1, A_{0}=A$, and $B_{0}=B$. We define $f, g: A \rightarrow B$ by

$$
f(0, m)= \begin{cases}(1,1), & m=\frac{1}{2} \\ \left(1, \frac{m}{2}\right), & m \neq \frac{1}{2},\end{cases}
$$

and $g(0, m)=(1,1)$. Also we define $\alpha: A \times A \rightarrow[0, \infty)$ by

$$
\alpha(p, q)= \begin{cases}2, & \text { if } p, q \in\left\{\left(0, \frac{1}{2}\right)\right\} \times A, \\ 0, & \text { otherwise }\end{cases}
$$

and $\psi:[0, \infty) \times[0, \infty) \rightarrow[0, \infty)$ by

$$
\psi(s, t)=\frac{1}{2}(s+t) \quad \text { for all } s, t \in X .
$$

It is easy to see that all the required hypotheses of Theorem 2.9 are satisfied unless (iii). Clearly $f$ and $g$ do not have a common best proximity point. It is worth noting that the pair $(f, g)$ does not have the triangular $\alpha$-proximal admissible property.

The authors declare that they have no competing interests. 


\section{Author details}

${ }^{1}$ Department of Mathematics, Behbahan Khatam Alanbia University of Technology, Behbahan, Iran. ${ }^{2}$ Department of Mathematics and Computer Science, Amirkabir University of Technology, Hafez Ave., P.O. Box 15914, Tehran, Iran.

${ }^{3}$ Department of Mathematics, Iran University of Science and Technology, Tehran, Iran.

Received: 23 September 2015 Accepted: 14 April 2016 Published online: 30 April 2016

\section{References}

1. Fan, K: Extensions of two fixed point theorems of F. E. Browder. Math. Z. 112, 234-240 (1969)

2. Kirk, WA, Reich, S, Veeramani, P: Proximinal retracts and best proximity pair theorems. Numer. Funct. Anal. Optim. 24 851-862 (2003)

3. Mongkolkeha, C, Sintunavarat, W: Best proximity points for multiplicative proximal contraction mapping on multiplicative metric spaces. J. Nonlinear Sci. Appl. 8(6), 1134-1140 (2015)

4. Haddadi, MZ: Best proximity point iteration for nonexpensive mapping in Banach spaces. J. Nonlinear Sci. Appl. 7(2), 126-130 (2014)

5. Di Bari, C, Suzuki, T, Vetro, C: Best proximity points for cyclic Meir-Keeler contractions. Nonlinear Anal. 69, 3790-3794 (2008)

6. Gabeleh, M: Proximal weakly contractive and proximal nonexpansive non-self-mappings in metric and Banach spaces. J. Optim. Theory Appl. 158, 615-625 (2013)

7. Akbar, F, Kutbi, MA, Shah, MH, Shafqat, N: Random coupled and tripled best proximity results with cyclic contraction in metric spaces. J. Nonlinear Sci. Appl. 9(3), 940-956 (2016)

8. Aydi, $\mathrm{H}$, Felhi, A, Karapınar, E: On common best proximity points for generalized $\alpha$ - $\psi$-proximal contractions. J. Nonlinear Sci. Appl. 9(5), 2658-2670 (2016)

9. Aydi, H, Felhi, A: Best proximity points for cyclic Kannan-Chatterjea-Ciric type contractions on metric-like spaces. J. Nonlinear Sci. Appl. 9(5), 2458-2466 (2016)

10. Sadiq Basha, S, Shahzad, N: Best proximity point theorems for generalized proximal contractions. Fixed Point Theory Appl. 2012, 42 (2012)

11. Suzuki, T, Kikkawa, M, Vetro, C: The existence of best proximity points in metric spaces with the property UC. Nonlinear Anal. 71, 2918-2926 (2009)

12. Pragadeeswarar, V, Marudai, M, Kumam, P: Best proximity point theorems for multivalued mappings on partially ordered metric spaces. J. Nonlinear Sci. Appl. 9(4), 1911-1921 (2016)

13. Latif, A, Abbas, $M$, Hussain, A: Coincidence best proximity point of $F_{g}$-weak contractive mappings in partially ordered metric spaces. J. Nonlinear Sci. Appl. 9(5), 2448-2457 (2016)

14. Kumam, P, Salimi, P, Vetro, C: Best proximity point results for modified $\alpha$-proximal C-contraction mappings. Fixed Point Theory Appl. 2014, 99 (2014)

\section{Submit your manuscript to a SpringerOpen ${ }^{\circ}$ journal and benefit from:}

- Convenient online submission

Rigorous peer review

- Immediate publication on acceptance

- Open access: articles freely available online

- High visibility within the field

- Retaining the copyright to your article 